Academic Platform Journal of Engineering and Science

\title{
Dinamik Simülasyonlarda Bölüntünün Geometrik Şeklinin Basınç Davranışına Etkisinin Araştırılması
}

\author{
${ }^{* 1}$ Hasan Hacıosmanoğlu, ${ }^{2}$ Gökhan Sevilgen, ${ }^{3}$ Emre İsa Albak \\ ${ }^{1}$ BMC Otomotiv Sanayi ve Ticaret A.Ş., İzmir, Türkiye, haciosmanoglu.hasan@gmail.com, \\ ${ }^{2}$ Uludağ Üniversitesi, Mühendislik Fakültesi, Otomotiv Mühendisliği, Bursa, Türkiye, \\ gsevilgen@uludag.edu.tr, \\ ${ }^{3}$ Uludağ Üniversitesi, Mühendislik Fakültesi, Otomotiv Mühendisliği, Bursa, Türkiye, \\ emrealbak@uludag.edu.tr,
}

$\ddot{\text { Öz }}$

Bu makalede, LS-DYNA sonlu elemanlar çözücüsü kullanılarak gerçekleştirilen dinamik simülasyonlarda, bölüntünün geometrik şeklinin, basıncın havadaki ilerleyişine ve büyüklüğüne etkisi incelenmiştir. İncelenen geometrik şekiller kübik, silindirik ve küresel olarak seçilmiştir. Dinamik simülasyonu modellemek için ALE metodu kullanılmıştır. Hedef bir noktadaki pik basınç değerleri, test sahasındaki dinamik testten elde edilen değer ile kıyaslanmıştır. Son olarak çalışmada belirtilen koşullarda hangi bölüntünün geometrik șeklinin daha doğru sonuçlar verebileceği değerlendirilmiştir.

Anahtar Kelimeler: Dinamik simülasyon, Arbitrary Lagrangian-Eulerian (ALE) yöntemi, sonlu elemanlar analizi, LS-DYNA

\section{Investigation of the Effect of Mesh Geometric Shapes on Pressure Behavior in Dynamic Simulations}

\author{
${ }^{* 1}$ Hasan Haciosmanoğlu, ${ }^{2}$ Gökhan Sevilgen, ${ }^{3}$ Emre İsa ALBAK \\ ${ }^{1}$ BMC Otomotiv Sanayi ve Ticaret A.S., Izmir, Turkey, haciosmanoglu.hasan@gmail.com \\ ${ }^{2}$ Uludağ University, Engineering Faculty, Dept. Of. Automotive Engineering, Bursa, Turkey, gsevilgen@uludag.edu.tr \\ 3Uludağ University, Engineering Faculty, Dept. Of. Automotive Engineering, Bursa, Turkey, emrealbak@uludag.edu.tr
}

\begin{abstract}
In this paper, the effect of the geometrical shapes of the mesh on the progress of pressure wave and magnitude was investigated in the dynamic simulations by using LS-DYNA finite element solver. Cubic, cylindrical and spherical geometrical shapes were chosen to be examined. ALE() method was carried out to model dynamic simulation. Peak pressure values at a target point were compared with the value obtained from the dynamic test in the test area. In conclusion, it was investigated that which mesh geometric shape could give more accurate results under the conditions specified in the study.
\end{abstract}

Keywords: Dynamic simulation, Arbitrary Lagrangian-Eulerian (ALE), Finite Element Analysis, LS-DYNA

\section{GİRIŞ}

Günümüzde, askeri alanda artan tehditlere karşı yapıların/askeri araçların koruma yeteneklerini artırmak amacıyla dinamik simülasyonlar yapılmaktadır. Dinamik yüklerinin hesaplanması için en bilinen yöntemlerden bir tanesi, LS-DYNA sonlu elemanlar kodu içerisinde bulunan Arbitrary Lagrangian-Eulerian (ALE) yöntemidir [12]. Bu yöntemde, enerji kaynağı ve hava Euler tipi elemanlarla modellenirken, hedef yapı Lagrange tipi elemanlarla modellenir. Enerji kaynağında açığa çıkan enerji, hava içerisinde ilerleyerek [10,11] ilgili kontak algoritmaları [15] yardımıyla hedef yapıya iletilir.

Z. S. Tabatabei [6] ve arkadaşları çalışmalarında, test sahasında beton panellere gelen dinamik yükün etkilerini incelerken enerji kaynağının oluşturduğu açık hava basıncını da ölçerek analiz çalışmaları ile karşılaştırmışlardır. S. A. 
Kilic [5] ve arkadaşları çalışmalarında, eleman çözünürlüğü, eleman topolojisi ve katı sıvı etkileşim parametrelerini incelemişlerdir. Simülasyon sonuçlarını Conwep yöntemi ile kıyaslamışlardır. Elde edilen sonuçlara göre küresel geometriye sahip hava hacmi ile ALE yöntemini kullanarak tam araç üzerinde dinamik yükleme analizi gerçekleştirmişlerdir. W. Xiao [7] ve arkadaşları çalışmalarında farklı konfigürasyonlardaki beton duvarların şok dalgasına karşı dayanımlarını, ALE metodu kullanarak incelemişlerdir. Çalışmada duvar arkasında kalan bölgedeki basınç değerlerini, LS-DYNA sonlu elemanlar kodu kullanılarak gerçekleştirilen dinamik analizler ile belirlemiş ve test sonuçları ile kıyaslamışlardır.

$\mathrm{Bu}$ çalışmada bir enerji kaynağından ortaya çıkan basınç dalgasının ilerleyişi hem nümerik olarak hem de deneysel olarak incelenmiştir. $\mathrm{Bu}$ çalışma kapsamında diğer çalışmalardan farklı olarak, hava hacmine ait geometrik şeklin kendi başına şok dalgasının ilerleyişine ve şiddetine etkisi incelenmiştir. Son olarak sonuçlar test ölçümü ile kıyaslanarak değerlendirme ve çıkarımlar yapılmıştır.

\section{MALZEME VE YÖNTEM}

\subsection{Deneysel Çalışma}

Deney çalışması, dinamik etkileri dış etkilerden arındırmak için açık havada ve açık arazide gerçekleştirilmiştir. Enerji kaynağı Şekil 1'de gösterildiği gibi, yerden $1 \mathrm{~m}$ yükseklikte konumlandırılmıştır. Basınçölçer sensör ise, enerji kaynağından yatayda $5 \mathrm{~m}$ uzaklığa konumlandırılmış olup, yerden yüksekliği, yer düzlemine çarparak oluşacak yansıma basıncından etkilenmemesi için enerji kaynağından daha yükseğe konumlandırılmıştır.

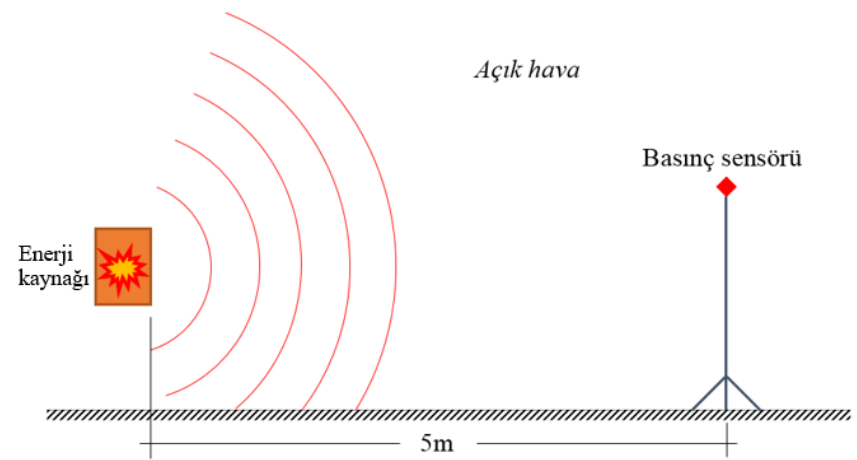

Şekil 1. Deney düzeneği şematik gösterimi

\subsection{Arbitrary Lagrangian-Eulerian Çözüm Metodu}

LS-DYNA sonlu elemanlar kodu içerisindeki ALE metodu, dinamik simülasyon modellerinde sıklıkla kullanılan bir metotdur [7,8]. Enerji kaynağı ve hava hacimleri, Euler tipi üç boyutlu elemanlarla modellenir ve ortak düğüm noktaları ile birbirlerine bağlıdırlar. Enerji kaynağı ve hava hacimleri, Euler formülasyonundan dolayı akışkan özellik göstermektedir. ALE yönteminde akışkan-katı (FSI) etkileşimleri gözlemlenebilmektedir [3,13]. Katı komponentler Lagrange tipi elemanlarla modellenirler ve akışkan hacimlerin içerisinde gömülü halde bulunmalarına karşın herhangi bir ortak düğüm noktaları bulunmamaktadır. Akışkanın yarattığı etkiler kontak algoritmaları ile katı yapıya iletilir [14]. Lagrange ve Euler tipi yapıların birbiriyle olan karşılıklı karşılıklı etileşimleri *ALE_MULTI_MATERIAL_GROUP kart1 ile sağlanmaktadır [8].

Yüksek enerjili kaynağın oluşturduğu basınç dalgası, enerji kaynağının malzeme modelinde tanımlanan hızda enerji kaynağı hacminde ilerler. Basınç enerji kaynağı-hava sınırına ulaştığında ortak düğüm noktaları vasıtası ile hava hacmine aktarılır ve ilerleyişine hava hacminde devam eder. Hedef yapı ile basınç dalgası etkileşimi LS-DYNA kodunda bulunan *CONSTRAINED_LAGRANGE_IN_SOLID fonksiyonu ile sağlanmaktadır. Akışkan-katı etkileşimi penalty formülasyonu temeline dayanmaktadır [1].

\subsection{Basınç Dalgası}

Açık havada gerçekleştirilen bir dinamik yüklemede, bir noktadaki basınç değerinin zamana bağlı olarak değişimi incelendiğinde, şok dalgası sebebiyle ani ve dik bir artışın ardından eksponansiyel eğri benzeri bir azalış göstermektedir. Kısa bir süre atmosferik basınç değerinin altında kaldıktan sonra (vakum etkisi), atmosferik basınç değerinde dengeye gelmektedir. Basınç şok dalgasının basınç-zaman profili Şekil 2'de gösterilmiştir.

Ölçülen en yüksek basınç $P_{\max }$ ile atmosferik basınç $P_{A}$ arasındaki fark, pozitif aşırı basınç (overpressure) $P_{0}$ olarak ifade edilmiştir. Ampirik düzeltme faktörünün eklendiği, zamana bağlı basınç değişimini ifade eden denklem (1)'de verilmiştir [2].

$P(t)=P_{0}\left(1-\frac{t}{t_{d}}\right) e^{-\alpha\left(\frac{t}{t_{d}}\right)}$

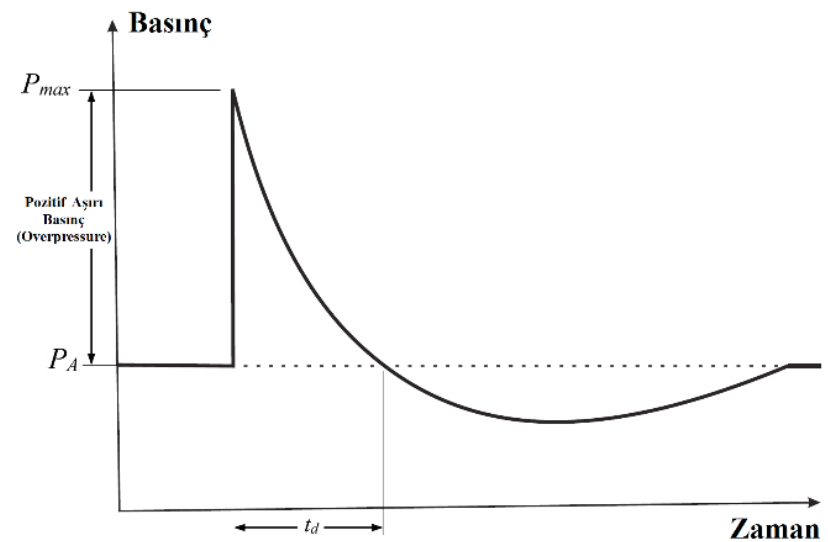

Şekil 2. Basınç şok dalgasının basınç-zaman profili

Burada $\alpha$ azalım parametresi, $t$ zaman, $P, t$ anındaki basınç değeri, $P o$ maksimum aşırı basınç, $t_{d}$ pozitif faz süresi, $e$ doğal logaritma tabanıdır. Kinney [2], azalım parametresini farklı $\frac{P}{P_{0}}$ ve $\frac{t}{t_{d}}$ değerleri için çalışmasında sunmaktadır. Basınç impuls değeri ile azalım parametresi arasındaki bağıntı formülü (2)'de verilmektedir.

$I=\int_{0}^{t_{d}} P(t) d t\left[\frac{1}{\alpha}-\frac{1}{\alpha^{2}}\left(1-e^{-\alpha}\right)\right]$ 


\subsection{Malzeme Bilgisi}

Analiz çalışmasında, enerji kaynağı modellenirken *MAT_HIGH_EXPLOSIVE_BURN malzeme kartı kullanılmıştır. Malzeme kartının yanında hal denklemi de kullanmak gerekmektedir. LS-DYNA kodu içerisinde enerji kaynağı malzemelerin madellenmesinde *EOS_JWL kartı kullanılmaktadır [1]. Jones-Wilkins-Lee (JWL) durum denklemi, enerji kaynağının ateşlenmesinden sonraki safhada, enerji kaynağının enerjisinin ortama aktarılması ve şok dalgalarının hareketini açıklayan ampirik bir denklemdir. Bu denkleme göre basınç, bağıl hacim ve birim hacim başına düşen enerjiye bağlı olarak değişmektedir (3) $[1,9]$.

$P=A\left[1-\frac{w}{R_{1} V}\right] e^{-R_{1} V}+B\left[1-\frac{w}{R_{2} V}\right] e^{-R_{2} V}+\frac{w E_{0}}{V}$

Burada $P$ basınç, $V$ bağıl hacim, $E_{0}$ özgül iç enerjidir. $R_{l}, R_{2}$, $A, B$ malzeme değişkenleridir. Bağıl hacim $V=\frac{v}{v_{0}}$ olarak ifade edilirken, $v_{0}$ tepkime öncesi enerji kaynağının ilk hacmidir. Enerji kaynağının malzeme bilgileri, Dobratz ve Crawford [4] tarafindan çalışmalarında sunulmuştur. Bu değerler Tablo 1'de paylaşılmıştır. İnflak hızı $D, P_{C J}$ Chapman-Jouguet enerji kaynağı basıncı, $\rho_{0}$ ilk yoğunluk olarak verilmiştir. İnflak süreci, LS-DYNA kodu içerisinde bulunan programlanmış ateşleme yaklaşımı ile başlatılır. Inflak, programda uygulayıcı tarafindan belirtilen noktada başlayarak, yüksek enerji kaynağı malzeme içerisinde sabit $D$ hızı ile ilerler. İnflak tüm enerji kaynağı hacminde tamamlandıktan sonra hava hacmi ile etkilessim başlar ve oluşan basınç hava hacmine aktarılır.

Hava malzemesi *MAT_NULL malzeme kartı ile tanımlanmıştır. Hava malzeme modeli için gerekli olan durum denklemi lineer polinomal hal denklemidir ve (4) numaralı formül ile verilmiştir [3].

$P=C_{0}+C_{1} \mu+C_{2} \mu^{2}+C_{3} \mu^{3}+\left(C_{4}+C_{5} \mu+C_{6} \mu^{2}\right) E$

Burada $P$ basınç, index numarası 0-6 arasında değişen $C$ değerleri malzeme katsayılarıdır. $\mu$ değişkeni, (5) numaralı denklemde verildiği şekli ile hacimsel oranı, $E$ ise birim hacimdeki enerji değerini ifade etmektedir.

$\mu=\frac{\rho}{\rho_{0}}-1$

Gazlar için ideal gaz denklemine göre $\mathrm{C} 0=\mathrm{C} 1=\mathrm{C} 2=\mathrm{C} 3=$ C6 $=0$, C4 $=$ C5 $=\gamma-1$ 'dir. $\gamma$ özgül 1S1 oranını ifade etmektedir ve hava için 1.4 değerini almaktadır. Bu değerlere göre (4) numaralı denklem, aşağıdaki (6) numaralı denkleme dönüşmektedir.

$P=(\gamma-1) \frac{\rho}{\rho_{0}}$

\subsection{Bölüntünün Geometrik Şekilleri}

Çalışmada 3 farklı geometrik şekil ile analizler yapılmıştır. Kübik, silindirik ve küresel olarak seçilen bu geometrilere ait detaylar, Şekil 3'de paylaşılmıştır.

Enerji kaynağı tüm modellerde, deney çalışmasında olduğu gibi silindirik şekilde modellenmiştir, kütlesi ve boyutları sabit tutulmuştur. Karşılaştırmaların yapılacağı ve sonuçların inceleneceği geometriler hava hacmine aittir.

Tablo 1. Malzeme parametreleri

\begin{tabular}{|c|c|c|c|c|c|c|c|}
\hline & \multicolumn{7}{|c|}{$[\mathrm{mm}, \mathrm{kg}, \mathrm{ms}]$} \\
\hline \multirow{8}{*}{ Hava } & \multicolumn{7}{|c|}{ *MAT_NULL } \\
\hline & $R_{0}$ & $P_{C}$ & & & & & \\
\hline & $1.23 \mathrm{E}-9$ & 0.0 & & & & & \\
\hline & \multicolumn{7}{|c|}{ *EOS_LINEAR_POLINOMIAL } \\
\hline & $C_{0}$ & $C_{l}$ & $C_{2}$ & $C_{3}$ & $C_{4}$ & $C_{5}$ & $C_{6}$ \\
\hline & 0.0 & 0.0 & 0.0 & 0.0 & 0.4 & 0.4 & 0.0 \\
\hline & $E_{0}$ & & & & & & \\
\hline & $2.58 \mathrm{E}-4$ & & & & & & \\
\hline \multirow{6}{*}{$\begin{array}{c}\text { Enerji } \\
\text { Kaynağı }\end{array}$} & \multicolumn{7}{|c|}{ *MAT_HIGH_EXPLOSIVE_BURN } \\
\hline & Rho & $D$ & $P_{C J}$ & & & & \\
\hline & $1.63 \mathrm{E}-6$ & 6930.0 & 21.0 & & & & \\
\hline & \multicolumn{7}{|c|}{ *EOS_JWL } \\
\hline & $A$ & $B$ & $R_{1}$ & $R_{2}$ & Omeg & $E_{0}$ & $V_{0}$ \\
\hline & 371.213 & 3.231 & 4.15 & 0.95 & 0.3 & 7.0 & 1.0 \\
\hline
\end{tabular}
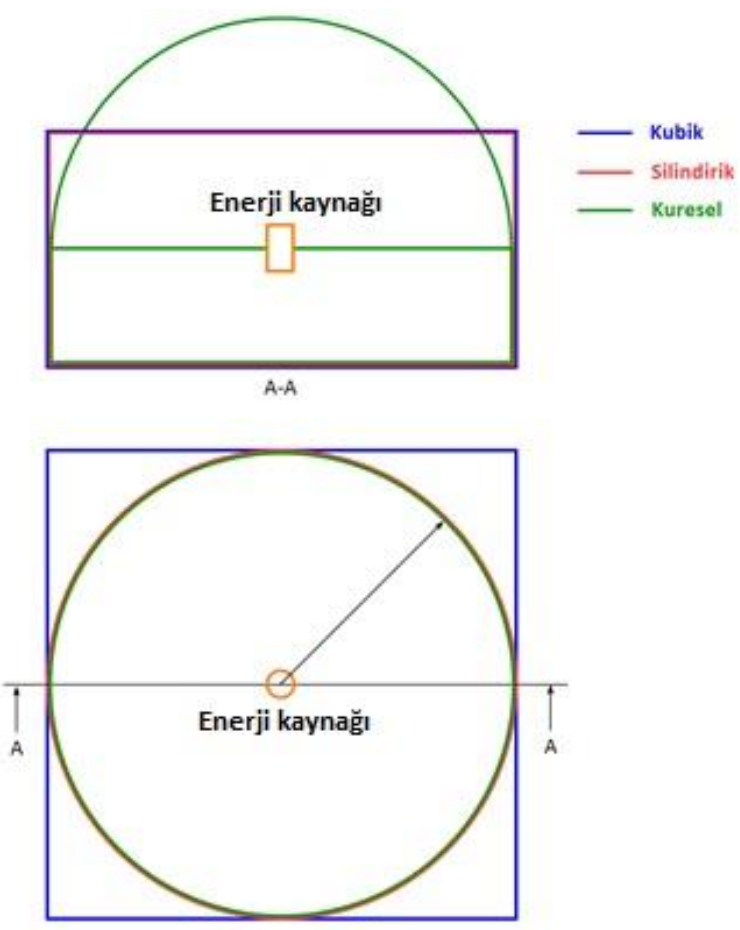

Şekil 3. Kübik, silindirik ve küresel geometriler şematik gösterimleri

Tüm geometrilerde hava ve enerji kaynağına ait euler hacimler, 8 düğüm noktalı altıyüzlü (hexahedral) elemanlarla modellenmiştir. Merkez konumda bulunan enerji kaynağı her zaman silindirik şekilde olduğundan; kübik ve küresel hava hacmi geometrisi elde edebilmek için enerji kaynağından hava hacmine geçişlerde, eleman diziliş doğrultularında düzenlemeler yapılmıştır. Silindirik hava hacmi geometrisi elde etmek için eleman diziliş doğrultularında herhangi bir değişiklik yapılmasına gerek duyulmamıştır. Her bir geometriye ait ağ yapısı, Şekil 4'de paylaşılmıştır. 



(a)

(b)

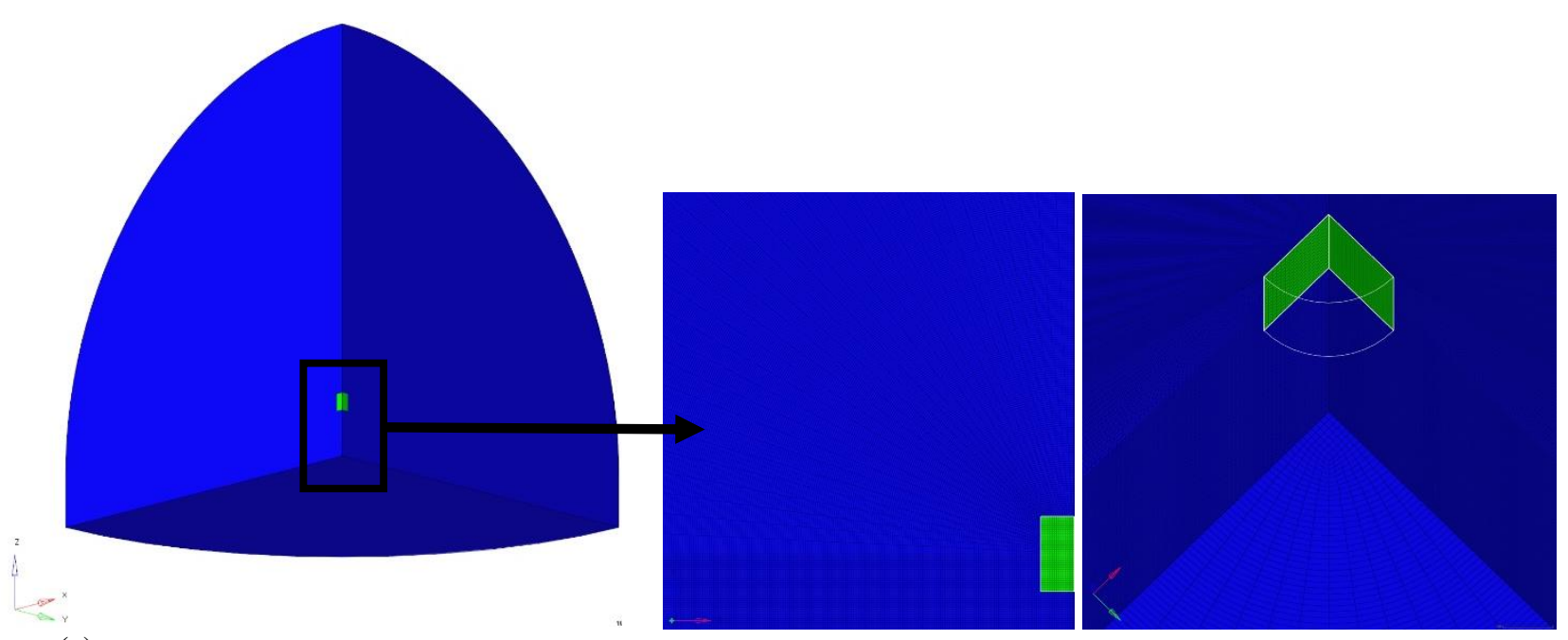

(c)

Şekil 4. (a) kübik, (b) silindirik ve (c) küresel ağ yapıları çeyrek model gösterimleri

Geometriler iki eksende simetrik olduğundan çözümlerde simetri koşulu uygulanarak çeyrek modeller kullanılmıştır.
Hesaplamalı akışkanlar mekaniği eşitlikleri, Euler hacimlerde genellikle yüksek eleman çözünürlüğüne gereksinim duymaktadır. Bunun anlamı, eleman boyutunun küçülmesi ile birlikte, analiz modelindeki eleman sayısının 
artmasıdır. Dolayısıyla, yüksek hassasiyete sahip analiz çözümleri için gerekli olan depolama alanları ve analiz hesaplama süreleri dramatik olarak artmaktadır. Bu yüzden analiz modeli oluşturulurken, ağ yapısı için optimum eleman boyutu belirlemek gerekmektedir. Bunu "bölüntü hassasiyet analizi" olarak isimlendirmek mümkündür. $\mathrm{Bu}$ çalışmada bölüntü hassasiyet analizi yapılmamış olup, bu konuda literatürden çalışmalar incelenerek uygun eleman boyutu belirlenmiştir [5]

Enerji kaynağı hacminde eleman kenar uzunlukları, birbirine eşit sayılabilecek uzunluklarda modellenebilirken, silindirik ve küresel hava hacimlerinde elemanlar radyal yönlerde büyümektedir. Kübik hava hacminde ise elemanlar, kenar uzunluk oranı 1'e çok yakın olacak şekilde modellenebilmektedir.

Sonuçlara etkilerini görmek amacıyla, seçilen eleman boyutunu 4 kat büyüterek oluşturulan modellerle de analizler yapılmıştır. Sonraki bölümlerde, seçilen eleman boyutu $d, 4$ kat büyütülen eleman boyutu $4 d$ olarak isimlendirilecektir.

Modellere ait eleman sayıları Tablo 2'de verilmiştir.

Tablo 2. Analiz modellerine ait eleman ve düğüm noktası sayıları

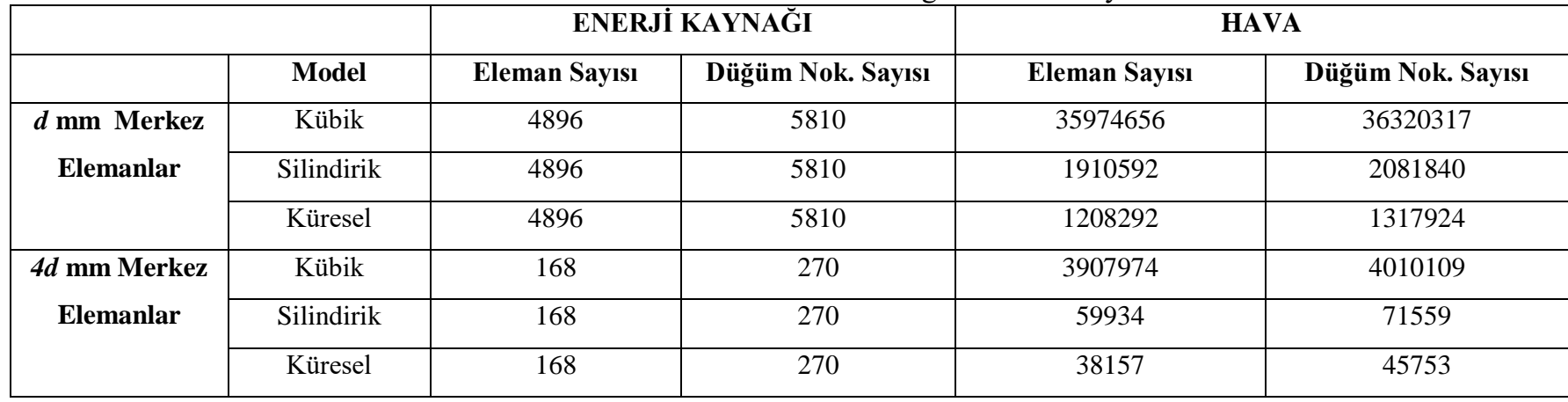

\section{BULGULAR}

\subsection{Dinamik Yükleme Analizi Sonuçları ve Deneysel Çalışma ile Kıyaslanması}

Kübik, silindirik ve küresel geometrilerin iki farklı eleman boyutu ile hazırlanan modelleri ile analizler gerçekleştirilmiştir. Öncelikle Şekil 5, Şekil 6 ve Şekil 7'de bu geometrilere ait $d \mathrm{~mm}$ elemanlarla hazırlanan çeyrek modellerde, şok basıncının zamana bağlı ilerleyişi görülmektedir. Kübik geometride, şok dalgası ilerleyişi sırasında yatayda enerji kaynağı hizasında daha hızlı yol aldığı, daha sonra ilerleyişin dengelendiği görülmektedir. Silindirik geometride, şok basıncı formu daha yumuşak geçişlere sahiptir. Küresel geometride ise, ağ yapısında eleman dizilişlerindeki doğrultu farkından dolayı şok basıncı formunun bozulduğu gözlemlenmektedir.

Şekil 8, Şekil 9 ve Şekil 10'da 4d mm elemanlarla hazırlanan çeyrek modellerde, şok basıncının zamana bağlı ilerleyişi görülmektedir. Genel olarak tüm $4 d \mathrm{~mm}$ elemanlarla hazırlanan geometriler $d \mathrm{~mm}$ elemanlarla hazırlanan geometrilerle karşılaştırıldığında, ilerleyişlerin benzer olduğu görülmektedir. Ancak eleman yoğunluğu yüksek olan $d \mathrm{~mm}$ elemanlarla hazırlanmış geometrilerde, şok basıncının havadaki dağılımı daha detaylı olarak görülebilmektedir. Şekil 11'de, dinamik yükleme testi sırasında ölçülen maksimum değer ile ölçüm alınan bu noktanın analiz modelinde karşılık gelen konumundan alınan basınç-zaman eğrileri, Tablo 3'de ise bu değerler ve test ölçümüne göre sapma yüzdeleri paylaşılmıştır.

Eğriler incelendiğinde, basınç şok dalgasının ölçüm noktasına ulaşma sürelerinde farklılıkların olduğu gözlemlenmiştir. Aynı eleman boyutuyla modellenen farklı geometrilerde, kübik geometriye sahip modelde basınç şok dalgası en hızlı şekilde ölçüm noktasına ulaşırken, küresel geometriye sahip modelde en geç ulaşmaktadır. Farklı eleman boyutuyla hazırlanan aynı geometrideki modellere bakıldığında ise, küçük eleman boyutuyla hazırlanan modellerde basınç şok dalgası ölçüm noktasına daha hızlı ulaşmaktadır.

Maksimum basınç değerleri incelendiğinde $\mathrm{d} \mathrm{mm}$ boyutlu modellerin 4d eleman boyutlu modellere göre daha iyi sonuçlar verdiği görülmektedir. $\mathrm{Bu}$ durumun nedeni, boyutların küçülmesi ile birlikte hesaplama noktası sayısının artmas1, dolayısıyla daha hassas hesaplama ile birlikte, analiz sonuçlarının bir miktar değişmesidir.

Geometrik yapıların maksimum basınç değerlerine etkisi incelendiğinde ise test değerine en yakın sonucu d boyutlu da küresel geometri vermesine rağmen $4 \mathrm{~d}$ boyutluda ise en kötü sonucu vermiştir. Bu hatanın küresel hava hacimlerinde elemanların radyal yönlerde büyümesi gösterilebilir. Kübik ve silindirik geometriler kıyaslandığında ise aynı eleman boyutunda silindirik geometri daha iyi sonuç vermiştir. Hava hacmi geometrisinin sonuçları etkilemesinin sebebi, hava hacminin geometrik şekline göre eleman akışının değişiyor oluşudur. 



Şekil 5. $d$ mm eleman boyutuna sahip kübik geometri modelinde şok basıncının ilerleyişi

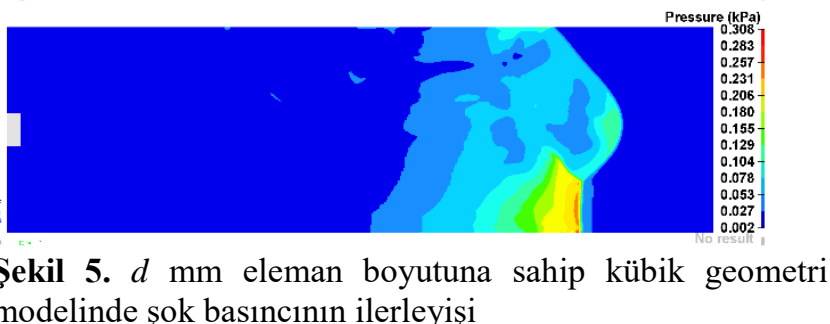

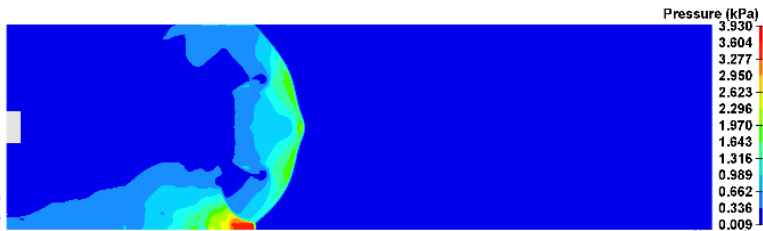
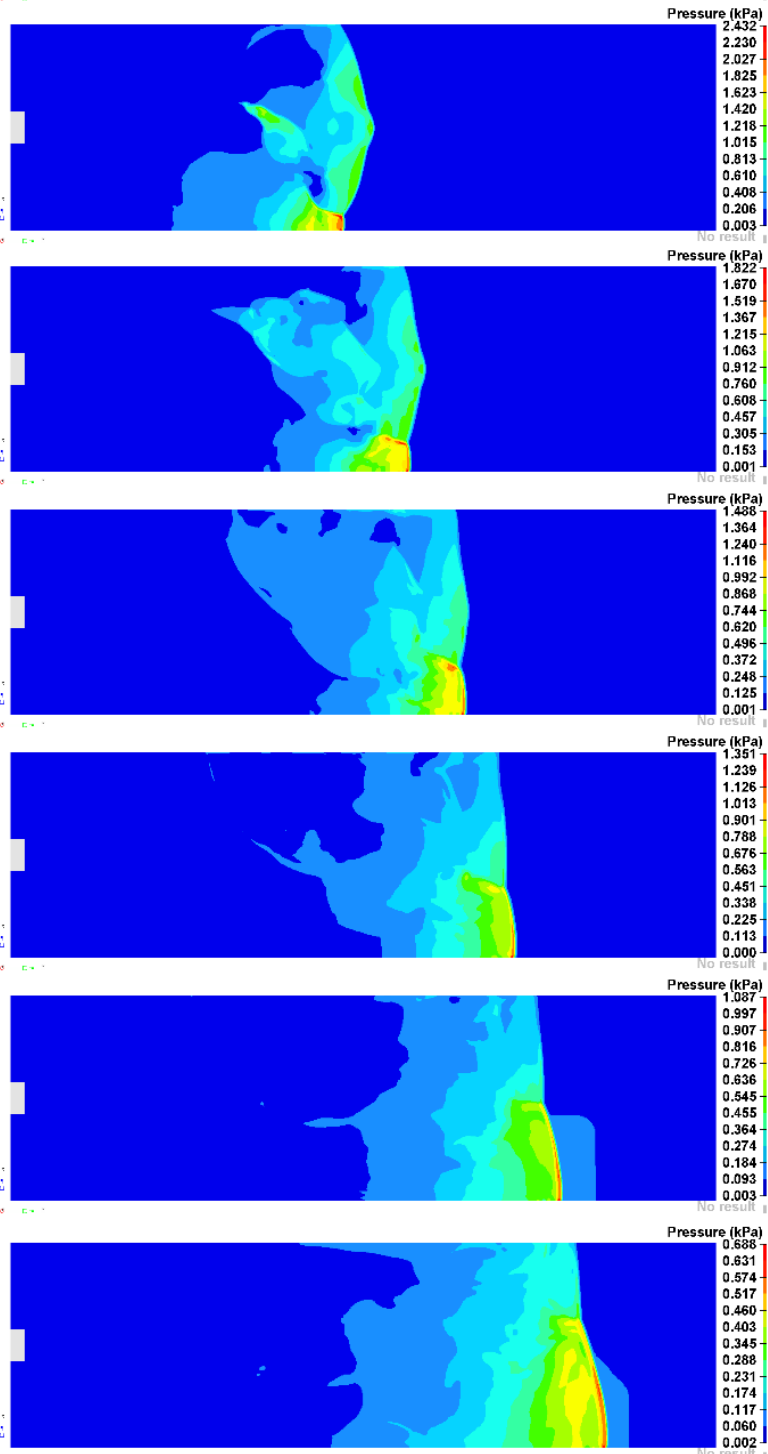

Şekil 6. $d$ mm eleman boyutuna sahip silindirik geometri modelinde şok basıncının ilerleyişi 

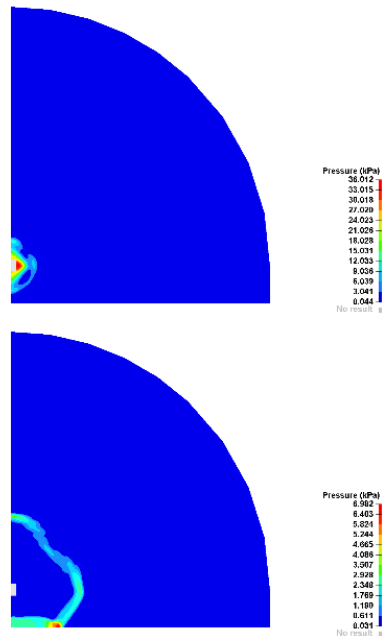

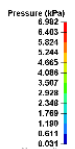
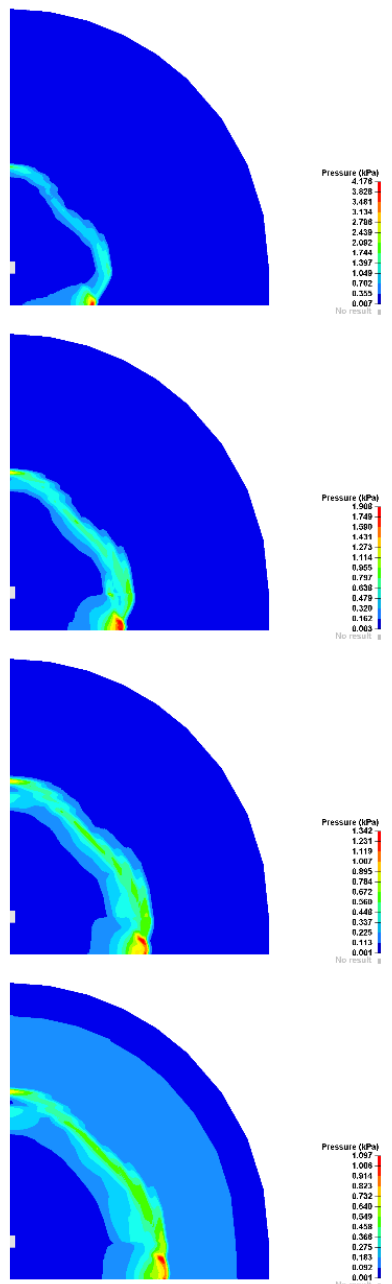

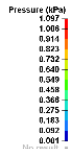
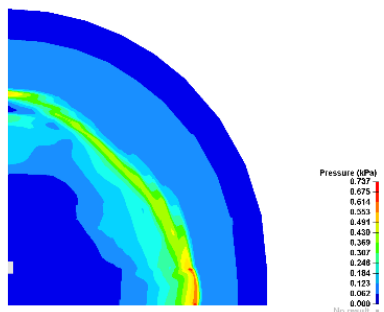

Şekil 7. $d$ mm eleman boyutuna sahip küresel geometri modelinde şok basıncının ilerleyişi
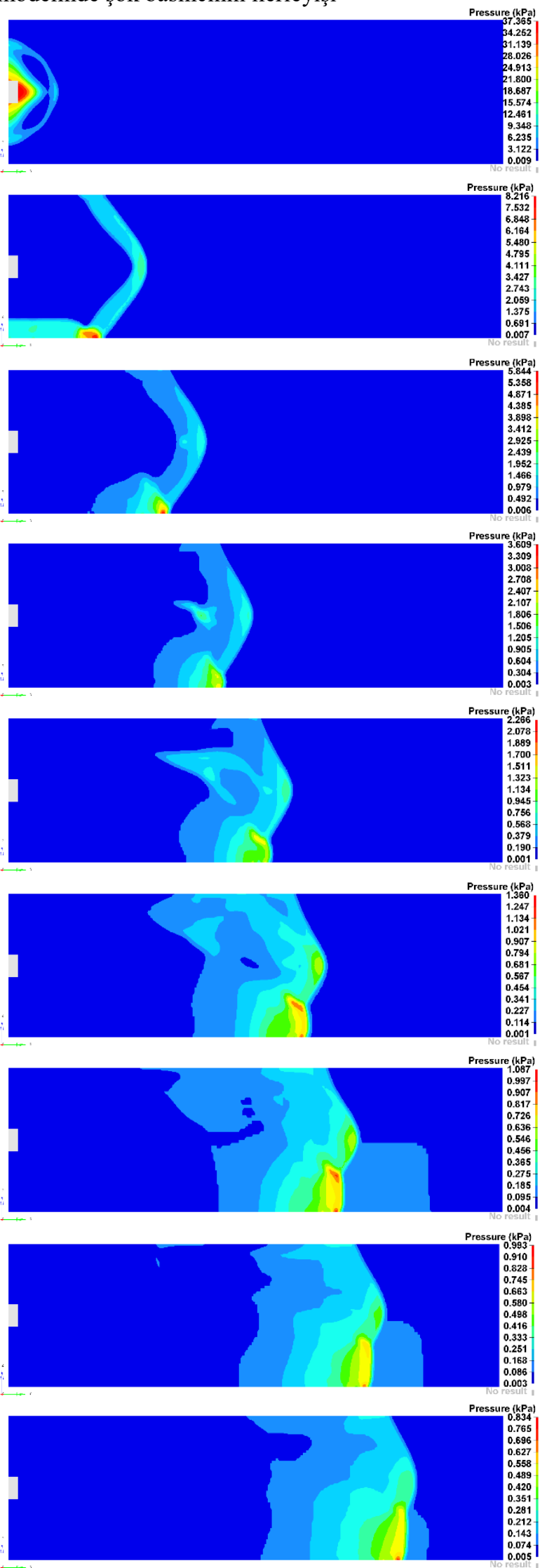
Şekil 8. $4 d \mathrm{~mm}$ eleman boyutuna sahip kübik geometri modelinde şok basıncının ilerleyişi
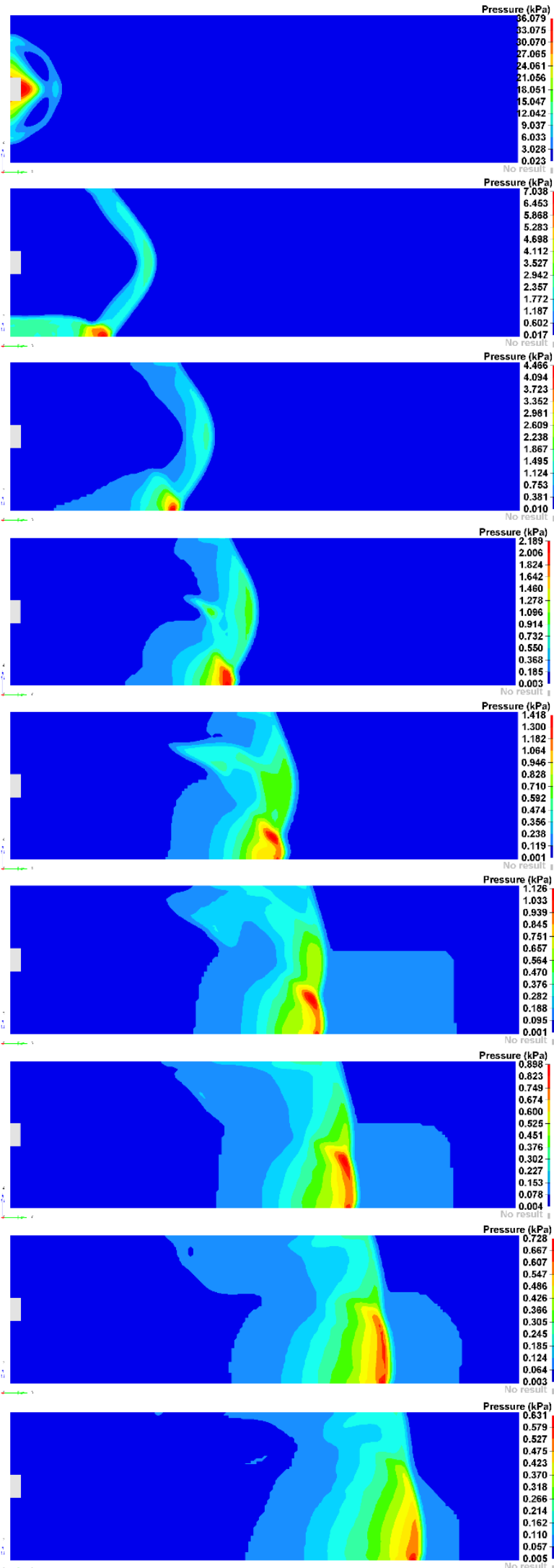

Şekil 9. $4 d \mathrm{~mm}$ eleman boyutuna sahip silindirik geometri modelinde şok basıncının ilerleyişi
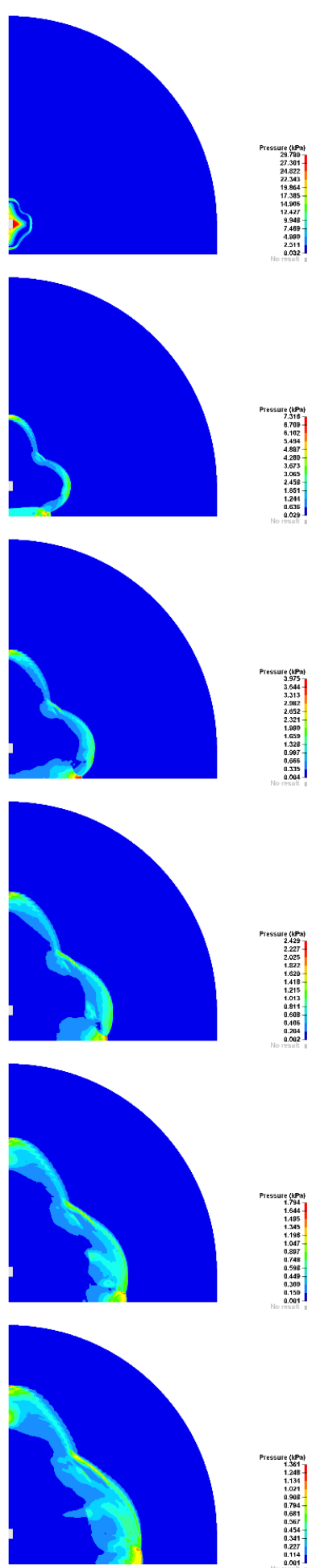


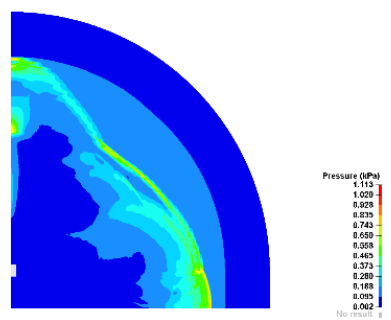

Şekil 10. $4 d \mathrm{~mm}$ eleman boyutuna sahip küresel geometri modelinde şok basıncının ilerleyişi

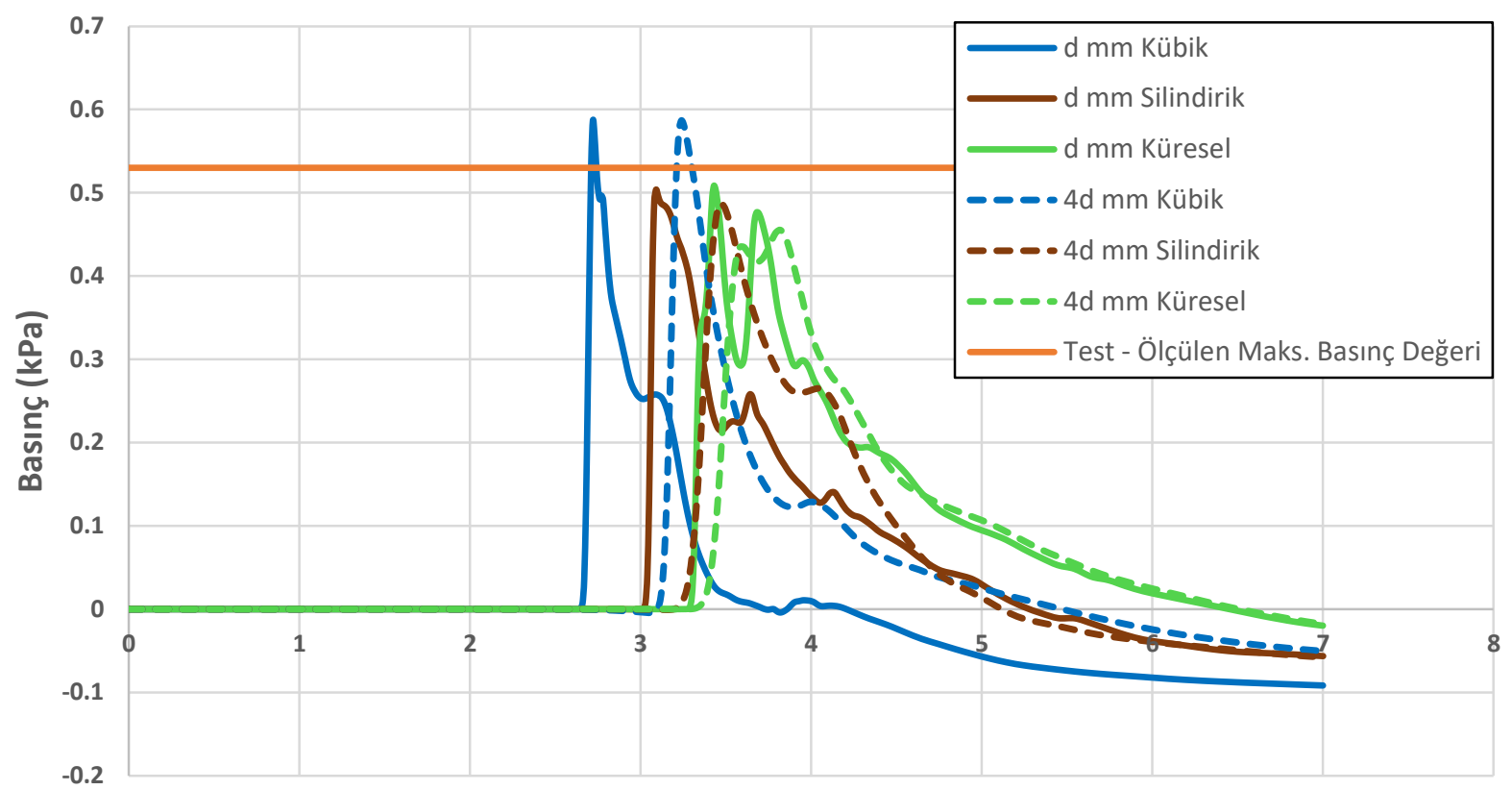

Zaman (ms)

Şekil 11. Şok basıncının ölçüm noktasındaki zamana bağlı değişimi - Test maksimum ölçüm değeri

Tablo 3. Analizler ile hesaplanan eğri maksimumlarının test ölçümüne karşılık sapma yüzdeleri

\begin{tabular}{|l|c|c|}
\hline & Maksimum Basınç [kPa] & \% Sapma \\
\hline d mm Kübik & 0.586 & -5.09 \\
\hline d mm Silindirik & 0.503 & -4.15 \\
\hline d mm Küresel & 0.508 & 10.75 \\
\hline 4d mm Kübik & 0.587 & -8.11 \\
\hline 4d mm Silindirik & 0.487 & -14.15 \\
\hline 4d mm Küresel & 0.455 & 0.00 \\
\hline Test & 0.53 & \\
\hline
\end{tabular}

\section{DEĞERLENDİRME VE SONUÇ}

$\mathrm{Bu}$ çalışmada LS-DYNA sonlu elemanlar kodu ile gerçekleştirilen analizler ile kübik, silindirik ve küresel geometriye sahip hava hacminin basınç şok dalgasının ilerleyişine ve büyüklüğüne etkisi incelenmiştir. Hedef yapının ve enerji kaynağının yerden yüksekliklerinin belirli aralıklarda olduğu durumlarda bu çalışma referans alınabilir. Analiz sonuçları incelendiğinde, geometrik değişimlerin ve sonlu elemanların büyüklüğünün basınç şok dalgasının ilerleme hızını ve büyüklüğünü etkilediği belirlenmiştir.
Hava hacmi geometrisinin sonuçları etkilemesinin sebebi, hava hacminin geometrik şekline göre eleman akışının değişiyor oluşudur. Sonlu eleman boyutunun sonuçları etkilemesinin sebebi ise; boyutların küçülmesi ile birlikte hesaplama noktası sayısının artması, dolayısıyla daha hassas hesaplama ile birlikte, analiz sonuçlarının bir miktar değişmesidir. Yapılacak çalışmanın içeriğine göre, doğru sonuçlar elde edebilmek için hava hacminin geometrik şekline, sonlu elemanların büyüklügüüne, elemanların diziliş doğrultularına, eğer önemli ise basınç şok dalgasının ulaşma zamanına bakılması gerektiği anlaşılmıştır. 


\section{TEŞEKKÜR}

Bu çalışmada, sayısal sonuçların doğrulanmsı için gerekli test çalışmaları ve test verilerinin elde edilmesinde sağladığ 1 destekleri için BMC Otomotiv Sanayi ve Ticaret A.Ş., 'ye teşekkür ederiz.

\section{KAYNAKÇA}

[1] Hallquist, J., LS-DYNA keyword user's manual Version 970, Livermore Software Technology Corporation, Livermore, 2012.

[2] G. F. Kinney and K. J. Graham, "Explosive Shocks in Air," 1985.

[3] J.O. Hallquist, LS-DYNA Theory Manual, Livermore Software Technology Corporation, California, USA, 2006.

[4] B. Dobratz, "Properties of chemical explosives and explosive simulants," 1972.

[5] A. Erdik, S. A. Kilic, N. Kilic, and S. Bedir, "Erratum to: Numerical simulation of armored vehicles subjected to undercarriage landmine blasts," Shock Waves, vol. 26, no. 4, pp. 531-531, 2016.

[6] Z. S. Tabatabaei, J. S. Volz, J. Baird, B. P. Gliha, and D. I. Keener, "Experimental and numerical analyses of long carbon fiber reinforced concrete panels exposed to blast loading," International Journal of Impact Engineering, vol. 57, pp. 70-80, 2013.

[7] W. Xiao, M. Andrae, L. Ruediger, and N. Gebbeken, "Numerical prediction of blast wall effectiveness for structural protection against air blast," Procedia Engineering, vol. 199, pp. 2519-2524, 2017.

[8] A. Alia and M. Souli, "High explosive simulation using multi-material formulations," Applied Thermal Engineering, vol. 26, no. 10, pp. 1032-1042, 2006.

[9] M. S. Chafi, G. Karami, and M. Ziejewski, "Numerical analysis of blast-induced wave propagation using FSI and ALE multi-material formulations," International Journal of Impact Engineering, vol. 36, no. 10-11, pp. 1269-1275, 2009.

[10] G. F. Kinney and K. J. Graham, Explosive Shocks in Air. Berlin: Springer Berlin, 2014.

[11] P. S. Bulson, "A history of research and a review of recent developments," Explosive Loading of Engineering Structures, 1997.

[12] T. Belytschko, D. Flanagan, and J. Kennedy, "Finite element methods with user-controlled meshes for fluidstructure interaction," Computer Methods in Applied Mechanics and Engineering, vol. 33, no. 1-3, pp. 669-688, 1982.

[13] W. Noh, "Cel: A Time-Dependent, Two-SpaceDimensional, Coupled Eulerian-Lagrange Code,” 1963.

[14] N. Aquelet, M. Souli, J. Gabrys, and L. Olovson, “A new ALE formualtion for sloshing analysis," Structural Engineering and Mechanics, vol. 16, no. 4, pp. 423-440, 2003.

[15] P. Woodward and P. Colella, "The numerical simulation of two-dimensional fluid flow with strong shocks," Journal of Computational Physics, vol. 54, no. 1, pp. 115-173, 1984. 